\title{
On the Robustness of Higher Order Risk Preferences*
}

\author{
Cary Deck \\ University of Arkansas \\ Chapman University
}

\author{
Harris Schlesinger \\ University of Alabama
}

October 2016

\begin{abstract}
Economists have begun to recognize the role that higher order risk preferences play in a variety of settings. As such, several experiments have documented the degree of prudence, temperance, and to a lesser extent, edginess and bentness that laboratory subjects exhibit. More recently, researchers have argued that higher order risk preferences generally conform to mixed risk averse and mixed risk loving patterns that arise from a preference for disaggregating or aggregating harms, respectively. This paper examines the robustness of this pattern in three ways. First, it attempts to directly replicate previous results with compound lotteries over monetary outcomes. Second, it compares behavior in compound lotteries with behavior in reduced form lotteries. And third, it evaluates choices over monetary and non-monetary risks. While previous results are replicated for compound lotteries over monetary outcomes and aggregate behavior with reduced form lotteries has a similar pattern, individuals clearly treat compound and reduced form lotteries differently. Further, behavior differs between monetary and non-monetary outcomes.
\end{abstract}

Keywords: Risk apportionment, mixed risk aversion, prudence, temperance, edginess, experiments JEL Codes: C9, D8

\footnotetext{
* Due to his untimely passing, Harris Schlesinger was unable to see this project through to completion. The paper is dedicated to his memory, but he should not be held accountable for its errors. We thank Sebastian Ebert for helpful feedback. Correspondence should be directed to cdeck@walton.uark.edu
} 


\section{Introduction}

Notions of risk have long been central to discussions of economics behavior, but to date relatively little attention has been paid to the role of higher (than second) order risk attitudes. One exception is the relevance of prudence, a third order risk property, in precautionary savings (see Leland 1968; Sadmo 1970; Dréze and Modiglianai 1972; and Kimball 1990). Recently, there has been a flurry of behavioral interest in measuring higher order risk attitudes. This effort largely stems from the theoretical work of Eeckhoudt and Schlesinger (2006) and Eeckhoudt, et al. (2009) which developed a method for classifying higher order risk attitudes based on binary comparisons that involved apportioning lower order risks. In the laboratory, the most common finding is that people tend to be risk averse, prudent, and to a lesser degree temperate (see Deck and Schlesinger 2010; Ebert and Wiesen 2011, 2014; Maier and Rüger 2012; Noussair, Trautman, and van de Kuilen 2014; and Baillon et al. 2016). ${ }^{1}$ Deck and Schlesinger (2014) go further, reporting evidence of choices consistent with either mixed risk aversion or mixed risk loving. The term mixed risk aversion, introduced by Caballé and Pomansky (1995), applies to an individual who dislikes an increase in risk of any degree, while the term mixed risk lover, introduced by Crainich, et al. (2013), describes an individual who dislikes increased risk for odd orders, but like increased risk in even orders. That the two types have similar preferences for odd orders but not even, may help explain why the experimental evidence for prudence is stronger than that for temperance.

As researchers are exploring the theoretical and behavioral properties of higher order risk preferences, it is important to understand the robustness of these preferences. This paper attempts to do so in three ways. First, it offers a direct replication of some of the tasks used in Deck and Schlesinger (2014). Second, it examines the degree to which the presentation format of the lottery impacts observed higher order risk attitudes. Specifically, we compare higher order risk apportionment tasks where choices are presented as compound lotteries with tasks where the choice is presented in reduced form. Harrison et al. (2015) demonstrate that (second order) risk taking behavior varies based on whether or not compound or reduced form lotteries are used. This design choice is potentially even more important for higher order risk attitudes where the study instrument is designed as a choice between aggregating and disaggregating harms. In fact, Deck and Schlesinger (2014, pp. 1921-1922) state "[Compound lottery] presentation admittedly also facilitates viewing the problem as 'combining good with bad' or 'combining good with good,' rather than presenting the lotteries in a reduced form, which might obfuscate this interpretation." To our knowledge, the only other paper that directly compares presentation formats for higher order risk problems is Haering et al. (2015). ${ }^{2}$ The results of their experiments suggest that subjects choose the prudent and temperate options less frequently when lotteries are presented in reduced form. Further, the reduction in temperate choices is sufficiently strong for the authors to conclude that with the reduced form presentation there is no evidence that subjects are generally temperate.

\footnotetext{
${ }^{1}$ Deck and Schlesinger (2010) and Baillon et al. (2016) found a majority of respondents were intemperate.

${ }^{2}$ Haering et al. (2015) also test for effects of stake size and geographic locations. They report behavior that is largely consistent with Deck and Schlesinger (2014) for subjects in the US, Germany, and China as well as with the use of higher stakes.
} 
The third way in which this paper examines the robustness of higher order risk attitudes is by combining monetary and non-monetary risks. If people have inherent preferences for disaggregating bad outcomes or aggregating good outcomes, these should be manifest in choices over different domains. In this study, we combine financial risks with a risky food choice. The specific food risk uses the Bean Boozled candy from Jelly Belly, which involves indistinguishable appearing jelly beans that have dramatically different tastes. One can find thousands of videos on youtube.com of people enjoying the "Tasty" flavors and spitting out the "Weird" flavors. To our knowledge, the only other paper that investigates apportionment of monetary and non-monetary risks is Ebert and van de Kuilen (2015). They presented some subjects with lotteries over waiting time (before being dismissed from the experiment) and cash prizes. The results suggest that people are generally cross-prudent and crosstemperate and tend to exhibit either mixed risk averse or mixed risk loving behavior. Ebert and van de Kuilen (2015) also examine risk apportionment with risks over one's own payoff and risks over the payoff of others. ${ }^{3}$ Here the evidence is less consistent, but as the authors note the notion of a good and a bad outcome may be confounded with subject concerns about relative payoffs.

The remainder of the paper is organized as follows. Section 2 provide the theoretical background for the study. Section 3 details the experimental design and Section 4 provides an analysis of the results. Section 5 offers a concluding discussion.

\section{Background Discussion}

The now standard approach for classifying higher order risk attitudes is due to Eeckhoudt and Schlesinger (2006) and Eeckhoudt et al. (2009). ${ }^{4}$ The approach relies on identifying how people apportion risk. Consider an individual with initial wealth $\mathrm{X}$ who faces two equally likely possible states of the world and who prefers more to less. The individual faces a choice about whether to aggregate or disaggregate two events, denoted $\varepsilon$ and $\delta$, in the sense of having them occur in the same or in different states. For example, if $\varepsilon$ and $\delta$ are certain losses then a risk averse person would prefer to experience the losses in different states. Using the notation $\left[\mathrm{O}_{1}, \mathrm{O}_{2}\right]$ to represent the lottery where the outcome is $\mathrm{O}_{1}$ with $50 \%$ probability and $\mathrm{O}_{2}$ with $50 \%$ probability, the statement is that a risk averse person prefers $[X+\varepsilon, X+\delta]$ to $[X, X+\varepsilon+\delta]$. Prudence can be identified as a preference for $[X+\varepsilon, X+\delta]$ over $[X, X+\varepsilon$ $+\delta$ ] when $\varepsilon$ is a zero mean risk and $\delta$ is a certain loss. Temperance can be identified as a preference for $[X+\varepsilon, X+\delta]$ over $[X, X+\varepsilon+\delta]$ when $\varepsilon$ and $\delta$ are both (independent) zero mean risks. Following Eeckhoudt et al. (2009), temperance can also be identified as a preference for $[X+\varepsilon, X+\delta]$ over $[X, X+\varepsilon$ $+\delta$ ] when $\varepsilon$ is a certain loss and $\delta$ has more third order risk. Deck and Schlesinger (2014) refer to the former identification of temperance as a $2+2$ construction and the later as $1+3$ construction. Higher order preferences can be constructed in a similar fashion by replacing $\varepsilon$ and $\delta$ with random variables that have appropriate order degree risk.

\footnotetext{
${ }^{3}$ Ebert and van de Kuilen (2015) also use risks incurred today with risks incurred in the future.

${ }^{4}$ Ebert et al. (2016) suggest a modified experimental approach to identifying higher order risk attitudes.
} 
At each order, the construction by Eeckhoudt and Schlesinger (2006) and Eeckhoudt et al. (2009) naturally leads to an interpretation of preferring to disaggregate harms. Moreover, if a person has a general preference for disaggregating harms, combining good with bad, then the individual will be risk averse, prudent, temperate, and satisfy risk apportionment of order $n$. This is mixed risk aversion as defined by Caballé and Pomansky (1995). By contrast, someone who has a general preference for combining good with good will exhibit risk apportionment of order $n$, when $n$ is even, but exhibit the opposite behavior when $n$ is odd. Referred to as mixed risk loving by Crainich, et al. (2013), people with such preference are risk loving and intemperate, but are prudent. This can easily be seen by recognizing that someone who prefers to combine the good outcome (and thus also prefers to combine the bad outcomes) would prefer $[\mathrm{X}, \mathrm{X}+\varepsilon+\delta]$ to $[\mathrm{X}+\varepsilon, \mathrm{X}+\delta]$ when $\varepsilon$ and $\delta$ are certain losses. But this mixed risk lover would prefer $[X+\varepsilon, X+\delta]$ to $[X, X+\varepsilon+\delta]$ when $\varepsilon$ is a zero mean risk as this is a good outcome as is the absence of the certain loss $\delta$. It should be noted that satisfying risk apportionment at one order does not necessarily imply risk apportionment of another order. However, one of the main behavioral findings in Deck and Schlesinger (2014) is that those who are risk averse tend to be mixed risk averters while those who are risk lovers tend to be mixed risk lovers suggesting that these pattern are behaviorally relevant. As should be clear from the above discussion, this process of constructing higher order risk choices involves compound lotteries and thus hinges on the validity of the independence axiom.

A natural extension of this approach is to correlation aversion (see Eeckhoudt et al. 2007). As described in Ebert and van de Kuilen (2015), the initial wealth $X$ above can be replaced with an ordered pair (X, Y) of initial endowments over two goods which need not be monetary. The two events $\varepsilon$ and $\delta$ can be viewed as shifting the initial values of $X$ and $Y$ respectively. Thus, when $\varepsilon$ and $\delta$ are certain losses in the different dimensions, a preference for $[(X+\varepsilon, Y),(X, Y+\delta)]$ over $[(X, Y),(X+\varepsilon, Y+\delta)]$ is consistent with correlation aversion. When the $\varepsilon$ is taken to be a zero mean risk for $X$, cross-prudence is a preference for $[(X+\varepsilon, Y),(X, Y+\delta)]$ over $[(X, Y),(X+\varepsilon, Y+\delta)]$. Higher order cross-risk apportionment can be identified in a similar manner.

\section{Experimental Design}

Upon entering the laboratory, subjects drew a slip of paper that identified their "Tasty" and "Weird" Jelly Belly Bean Boozled flavors. Table 1 gives the five flavor combinations that were used in the study. The subjects then were given a sample of both flavors. ${ }^{5}$ This process ensured that the subjects had experience with the flavors and made subsequent decisions regarding jelly beans salient. During this initial exposure, subjects were allowed to spit out jelly beans they did not wish to eat. Subjects were then seated at private workstations where they read the computerized instructions. ${ }^{6}$ In the instructions, subjects were informed that "If the randomly selected task for which you are to be paid involves a jelly

\footnotetext{
${ }^{5}$ Jelly beans in a flavors pair are visually indistinguishable. Some jelly beans were sliced open in advance to identify the actual flavor.

${ }^{6}$ Copies of the instructions are available in the appendix.
} 
bean, then you must chew and consume (keeping the chewed jelly bean in your mouth for 10 seconds) the appropriate jelly bean to receive any cash payment." ${ }^{7}$

Table 1. Tasty-Weird Jelly Belly Bean Boozled Flavor Pairs Used in Experiment

\begin{tabular}{cc} 
Tasty Flavor & Weird Flavor \\
\hline Buttered Popcorn & Rotten Eggs \\
Caramel Corn & Moldy Cheese \\
Coconut & Baby Wipes \\
Pear & Booger \\
Tutti Frutti & Stinky Socks
\end{tabular}

After finishing the instructions, subjects completed 52 tasks. For each subject, one task was randomly selected to determine that subject's payoff. The experiment involved three types of tasks. The first type was tasks taken from Deck and Schlesinger (2014), which involved cash payments and, if applicable, compound lottery presentation. ${ }^{8}$ The second type of task involved the same lotteries as in Deck and Schlesinger (2014), but presented in reduced form. The third type of task replaced 50-50 lotteries in Deck and Schlesinger (2014) with a 50-50 lottery over jelly bean flavors. Figure 1 presents some sample lotteries of each type as they were displayed to subjects. The probability of a given payoff is conveyed by the relative area of the circle associated with that outcome. In Figure 1, the choices presented in the first two rows are for the same lottery. The lottery in the third row replaces a 50-50 monetary lottery for $+\$ 2$ or $-\$ 2$ in the first row with a 50-50 non-monetary lottery for a weird or a tasty jelly bean. ${ }^{9}$ Selection of the jelly beans as an alternative medium for good and bad outcomes was deliberately selected to be comparable in scale to the $+\$ 2$ or $-\$ 2$ lottery. ${ }^{10}$ All of the higher order risk problems involving jelly beans were presented as compound lotteries. Throughout the paper, and following the convention in the literature, Option $A$ is of the form $[X+\varepsilon, X+\delta]$ while Option $B$ if of the form $[X, X+\varepsilon+$ $\delta]$.

\footnotetext{
${ }^{7}$ While several subjects spit out the weird flavor during the initial exposure, no one refused to eat a jelly bean as part of their final payment.

${ }^{8}$ First and second order tasks only involve fixed payments or simple 50-50 gambles.

${ }^{9}$ The lottery in the lower left tests for cross-prudence of for money relative to the jelly bean risk (see Ebert and van de Kuilen 2015).

${ }^{10}$ Smith (1982, p. 935) argues that non satiation, saliency, dominance and privacy are sufficient conditions for creating a microeconomic system and conducting a controlled theory testing experiment. These precepts are met for both the cash and jelly bean payoffs of this experiment.
} 
Figure 1. Sample Lottery Tasks

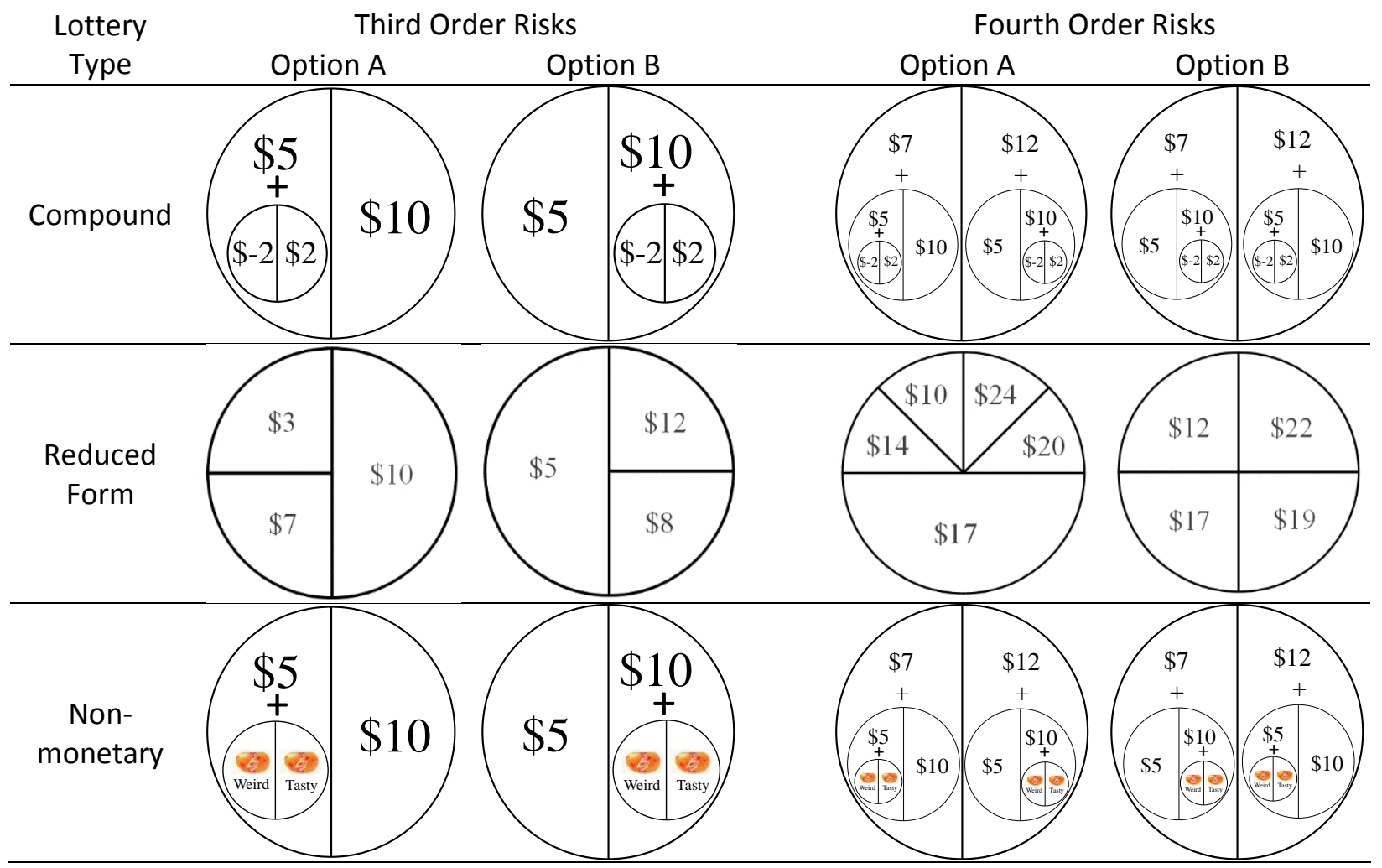

Figure 1 is also informative for the construction of higher order risk apportionment problems. The fourth order task in the figure combines the options in the third order task with a 50-50 lottery for either $\$ 7$ or $\$ 12$, thus in the terminology of Deck and Schlesinger (2014) this risk has a $3+1$ construction. Option A for the fourth order task combines option A for the third order task with the relatively bad outcome of $\$ 7$ and option $B$ for the third order task with the relatively good outcome of $\$ 12$. Option B for the fourth order task reverses the combination of the two components. A mixed risk averter would chose option B for the third order task as it combines the relatively bad lottery (as compared to a certain amount of $\$ 0$ ) with the good payoff of $\$ 10$ rather than the bad payoff of $\$ 5$. Thus the mixed risk averter would make the prudent choice. The mixed risk averter would thus also pick option $B$ for the fourth order task as it combines the good option from the third order choice with the relatively bad outcome of $\$ 7$ and the bad third order option with the good outcome of $\$ 12$. Hence, a mixed risk averter will make the temperate choice. A mixed risk lover who prefers to aggregate the goods prefers option $B$ in the third order task as it combines the good lottery (relative to a certain payoff of $\$ 0$ ) with the relatively good payoff of $\$ 10 .{ }^{11}$ Hence, the mixed risk lover makes the prudent choice. However, such a person would prefer option A in the fourth order task since it combines the good third order option B with the good payoff of $\$ 12$. Thus, the mixed risk averter will make the intemperate choice. Therefore, mixed risk averters and mixed risk loving people should make similar choices regarding prudence (and all other

${ }^{11}$ Notice that the risk averter and the risk lover view the 50-50 gamble over $-\$ 2$ and \$2 differently. 
odd order risk apportionment problems), but make different choices regarding temperance (and all other even order risk apportionment problems).

The full set of tasks is given in Table 2. The tasks were presented in a random order for each subject. Further, the computer software randomized which choice was shown on the left side of the screen and which was displayed on the right side of the screen.

Table 2. Binary Lottery Choice Pairs Used in Experiment

\begin{tabular}{|c|c|c|c|c|}
\hline Task & Order & Option A & Option B & Notes \\
\hline 1 & 1 & $\$ 20$ & $\$ 30$ & DS(1), Sum \\
\hline 2 & 1 & $\$ 2$ & $\$ 7$ & DS(2), Sum \\
\hline 3 & 2 & {$[\$ 5, \$ 15]$} & {$[\$ 10, \$ 10]$} & DS(4), Sum \\
\hline 4 & 2 & {$[\$ 2, \$ 12]$} & {$[\$ 10, \$ 4]$} & DS(5), Sum \\
\hline 5 & 3 & {$[\$ 5+[\$-2, \$ 2], \$ 10]$} & {$[\$ 5, \$ 10+[\$-2, \$ 2]]$} & $\mathrm{DS}(11)$ \\
\hline 6 & 2 & {$[\$ 2, \$ 7]$} & {$[\$ 5, \$ 4]$} & DS(7), Sum \\
\hline 7 & 3 & {$[\$ 5+[\$-4, \$ 4], \$ 10]$} & {$[\$ 5, \$ 10+[\$-4, \$ 4]]$} & $\mathrm{DS}(13)$ \\
\hline 8 & 3 & Same as Task 5 & Same as Task 5 & ROCL(5) \\
\hline 9 & 3 & {$[\$ 20+[\$ 10, \$-10], \$ 40]$} & {$[\$ 20, \$ 40+[\$ 10, \$-10]]$} & $\mathrm{DS}(15)$ \\
\hline 10 & 3 & Same as Task 7 & Same as Task 7 & $\mathrm{ROCL}(7)$ \\
\hline 11 & 4 & $\begin{array}{l}{[[\$ 14, \$ 20]+[\$ 14, \$ 20]} \\
[\$ 10, \$ 24]+[\$ 10, \$ 24]]\end{array}$ & $\begin{array}{l}{[[\$ 10, \$ 24]+[\$ 14, \$ 20]} \\
[\$ 14, \$ 20]+[\$ 10, \$ 24]]\end{array}$ & $\mathrm{DS}(18)$ \\
\hline 12 & 3 & Same as Task 9 & Same as Task 9 & ROCL(9) \\
\hline 13 & 1 & {$[\$ 2+[\$ 10, \$ 20], \$ 20]$} & {$[\$ 25, \$ 27+[\$-1, \$ 1]]$} & $\mathrm{DS}(3), \mathrm{ROCL}$ \\
\hline 14 & 4 & Same as Task 11 & Same as Task 11 & $\mathrm{ROCL}(11)$ \\
\hline 15 & 4 & {$[\$ 7+5 A, \$ 12+5 B]$} & {$[\$ 7+5 B, \$ 12+5 A]$} & $\mathrm{DS}(23)$ \\
\hline 16 & 4 & Same as Task 15 & Same as Task 15 & ROCL(15) \\
\hline 17 & 4 & Same as Task 19 & Same as Task 19 & ROCL(19) \\
\hline 18 & 4 & Same as Task 22 & Same as Task 22 & ROCL(22) \\
\hline 19 & 4 & $\begin{array}{l}{[[\$ 7, \$ 10]+[\$ 7, \$ 10]} \\
[\$ 5, \$ 12]+[\$ 5, \$ 12]]\end{array}$ & $\begin{array}{l}{[[\$ 5, \$ 12]+[\$ 7, \$ 10)],} \\
[\$ 7, \$ 10]+[\$ 5, \$ 12]]\end{array}$ & $\mathrm{DS}(19)$ \\
\hline 20 & 5 & Same as Task 25 & Same as Task 25 & ROCL (25) \\
\hline 21 & 5 & Same as Task 26 & Same as Task 26 & ROCL (26) \\
\hline 22 & 4 & {$[\$ 1+5 A, \$ 18+5 B]$} & {$[\$ 1+5 B, \$ 18+5 A]$} & $\mathrm{DS}(24)$ \\
\hline 23 & 5 & Same as Task 27 & Same as Task 27 & ROCL (27) \\
\hline 24 & 5 & Same as Task 28 & Same as Task 28 & ROCL (28) \\
\hline 25 & 5 & $\begin{array}{l}{[[\$ 7, \$ 10]+5 B} \\
[\$ 5, \$ 12]+5 A]\end{array}$ & $\begin{array}{l}{[[\$ 7, \$ 10]+5 A} \\
[\$ 5, \$ 12]+5 B]\end{array}$ & $\mathrm{DS}(25)$ \\
\hline 26 & 5 & $\begin{array}{l}{[[\$ 10, \$ 4]+[\$ 10, \$ 20+[\$-4, \$ 4]]} \\
[\$ 2, \$ 12]+[\$ 10+[\$-4, \$ 4], \$ 20]]\end{array}$ & $\begin{array}{l}{[[\$ 10, \$ 4]+[\$ 10+[\$-4, \$ 4], \$ 20]} \\
[\$ 2, \$ 12]+[\$ 10, \$ 20+[\$-4, \$ 4]]]\end{array}$ & $\mathrm{DS}(26)$ \\
\hline 27 & 5 & {$[\$ 5+19 A, \$ 7+19 B]$} & {$[\$ 5+19 B, \$ 7+19 A]$} & DS(29) \\
\hline 28 & 5 & $\begin{array}{l}{[\$ 1+[[\$ 10, \$ 4]+[\$ 7, \$ 10]} \\
[\$ 2, \$ 12]+[\$ 5, \$ 12]]\end{array}$ & $\begin{array}{l}{[\$ 1+[[\$ 2, \$ 12]+[\$ 7, \$ 10]} \\
[\$ 10, \$ 4]+[\$ 5, \$ 12]]\end{array}$ & $\mathrm{DS}(30)$ \\
\hline
\end{tabular}




\begin{tabular}{|c|c|c|c|c|}
\hline & & $\begin{array}{l}\$ 4+[[\$ 2, \$ 12]+[\$ 7, \$ 10] \\
[\$ 10, \$ 4]+[\$ 5, \$ 12]]]\end{array}$ & $\begin{array}{l}\$ 4+[[\$ 10, \$ 4]+[\$ 7, \$ 10] \\
[\$ 2, \$ 12]+[\$ 5, \$ 12]]]\end{array}$ & \\
\hline 29 & 3 & {$[\$ 8+[\$ 2, \$-2], \$ 10]$} & {$[\$ 8, \$ 10+[\$ 2, \$-2]]$} & $\mathrm{DS}(16)$ \\
\hline 30 & 4 & $\begin{array}{l}{[[\$ 1, \$ 16]+[\$ 1, \$ 16]} \\
[\$ 5, \$ 12]+[\$ 5, \$ 12]]\end{array}$ & $\begin{array}{l}{[[\$ 5, \$ 12]+[\$ 1, \$ 16]} \\
[\$ 1, \$ 16]+[\$ 5, \$ 12]]\end{array}$ & $\mathrm{DS}(21)$ \\
\hline 31 & 5 & $\begin{array}{l}{[[\$ 5, \$ 12]+[\$ 5, \$ 10+[\$-2, \$ 2],[\$ 1,} \\
\$ 16]+[\$ 5+[\$-2, \$ 2], \$ 10]]\end{array}$ & $\begin{array}{l}{[[\$ 5, \$ 12]+[\$ 5+[\$-2, \$ 2], \$ 10]} \\
{[\$ 1, \$ 16]+[\$ 5, \$ 10+[\$-2, \$ 2]]}\end{array}$ & $\mathrm{DS}(28)$ \\
\hline 32 & 2 & {$[\$ 4, \$ 10]$} & $\$ 7$ & $\mathrm{DS}(9)$ \\
\hline 33 & 2 & {$[\$ 1, \$ 19]$} & $\$ 10$ & $\mathrm{DS}(10)$ \\
\hline 34 & 3 & Same as Task 29 & Same as Task 29 & $\mathrm{ROCL}(29)$ \\
\hline 35 & 3 & Same as Task 38 & Same as Task 38 & $\mathrm{ROCL}\left(38^{*}\right)$ \\
\hline 36 & 4 & Same as Task 30 & Same as Task 30 & $\mathrm{ROCL}(30)$ \\
\hline 37 & 5 & Same as Task 31 & Same as Task 31 & $\mathrm{ROCL}(31)$ \\
\hline 38 & 3 & {$[\$ 12+[\$ 2, \$-2], \$ 14]$} & {$[\$ 12, \$ 14+[\$ 2, \$-2]]$} & $\mathrm{DS}\left(17^{*}\right)$ \\
\hline 39 & 1 & $\$ 5+$ Weird & $\$ 5$ & \\
\hline 40 & 1 & $\$ 5$ & $\$ 5+$ Tasty & \\
\hline 41 & 2 & $\$ 5+[$ Weird, Tasty] & $\$ 4$ & \\
\hline 42 & 2 & $\$ 5+[$ Weird, Tasty] & $\$ 5$ & \\
\hline 43 & 2 & $\$ 5+[$ Weird, Tasty] & $\$ 6$ & \\
\hline 44 & 3 & {$[\$ 5+[$ Weird, Tasty], \$10] } & {$[\$ 5, \$ 10+[$ Weird, Tasty $]]$} & $\mathrm{ST}(5,7)$ \\
\hline 45 & 3 & [Weird + [\$-2, \$2], Tasty] & [Weird, Tasty + $[\$-2, \$ 2]]$ & ST $(5,29,38)$ \\
\hline 46 & 3 & [Tasty, Weird + [Weird Tasty]] & [Tasty + [Weird Tasty], Weird] & \\
\hline 47 & 4 & {$[$ Weird + 5A, Tasty +5B] } & {$[$ Weird + 5B, Tasty + 5A] } & ST $(15,22)$ \\
\hline 48 & 4 & {$[\$ 7+44 \mathrm{~A}, \$ 12+44 \mathrm{~B}]$} & {$[\$ 7+44 \mathrm{~B}, \$ 12+44 \mathrm{~A}]$} & ST(15) \\
\hline 49 & 4 & {$[\$ 7+45 \mathrm{~A}, \$ 12+45 \mathrm{~B}]$} & {$[\$ 7+45 B, \$ 12+45 A]$} & ST(15) \\
\hline 50 & 5 & $\begin{array}{l}{[[\$ 7, \$ 10]+45 B} \\
[\$ 5, \$ 12]+45 A]\end{array}$ & $\begin{array}{l}{[[\$ 7, \$ 10]+45 A,} \\
[\$ 5, \$ 12]+45 B]\end{array}$ & ST(25) \\
\hline 51 & 5 & $\begin{array}{l}{[[\$ 7, \$ 10]+44 B} \\
[\$ 5, \$ 12]+44 A]\end{array}$ & $\begin{array}{l}{[[\$ 7, \$ 10]+44 A,} \\
[\$ 5, \$ 12]+44 B]\end{array}$ & ST(25) \\
\hline 52 & 5 & $\begin{array}{l}{[[\$ 5+\text { Tasty,\$10] + 5B, }} \\
[\$ 5, \$ 10+\text { Tasty }]+5 A]\end{array}$ & $\begin{array}{l}{[[\$ 5+\text { Tasty, } \$ 10]+5 A} \\
[\$ 5, \$ 10+\text { Tasty }]+5 B]\end{array}$ & ST(25) \\
\hline \multicolumn{5}{|c|}{$\begin{array}{l}{[\mathrm{X}, \mathrm{Y}] \text { denotes a lottery with a } 50 \% \text { chance of } \mathrm{X} \text { and a } 50 \% \text { chance of } \mathrm{Y} \text {. Task is the number associated with the }} \\
\text { task in the software and Order denotes the risk apportionment order of the task. DS(\#) denotes the task's \# in } \\
\text { Table } 2 \text { of Deck and Schlesinger (2014). Sum denotes that a payoff presented in Deck and Schlesinger (2014) } \\
\text { with two components was presented as a sum in the current study (e.g. } \$ 20+\$ 10 \text { now presented as } \$ 30) \text {. } \\
\text { ROCL(\#) denotes the reduced form of the compound lottery presented in Task \#. Task } 13 \text { was only presented in } \\
\text { reduced form. ST(\#) denotes a similar task where a monetary lottery has been replaced by a jelly bean lottery } \\
\text { (except for Task } 52 \text { where a tasty jelly bean substituted for a certain } \$ 2 \text { payment). * denotes that the } \$ \$ 1, \$-1] \\
\text { component of this lottery in Deck and Schlesinger (2014) was changed to }[\$ 2, \$-2] .\end{array}$} \\
\hline
\end{tabular}

Once the self-paced experiment was complete, the software randomly selected a task for payment. A researcher approached the subject with a mechanical spinner such as one might find in a child's board game. The spinner was divided into subsections based on the probabilities associated with the randomly selected task. The subject was allowed to spin the device, with the requirement that the 
spinner arrow go around several times to prevent manipulation. The subject was then paid in private and dismissed from the experiment.

A total of 53 subjects participated in the study, which was conducted at the Behavioral Business Research Laboratory at the University of Arkansas. The participants were drawn from the lab's standing subject pool and recruited for a one hour session. No mention was made during the recruitment process of the use of jelly beans or the nature of the experiment. No one chose not to participate after arriving at the lab. The average cash earnings were $\$ 16.66$ in addition to a $\$ 5$ participation payment that each subject received.

\section{Results}

The results are presented in three subsections. The first compares behavior observed in this study with that reported in Deck and Schlesinger (2014). The second, examines the degree to which presenting choices in reduced form rather than as compound lotteries impacts higher order risk taking. The third subsection focuses on the consistency of mixed risk behavior over monetary and non-monetary gambles.

\subsection{Replication of Previous Work}

One should always be cautious when drawing comparisons between studies. However, the current study and that of Deck and Schlesinger (2014) relied on the same subject pool, were conducted in the same lab, and employed the same experimental interface..$^{12}$ Of the 22 tasks that were included in this study and in Deck and Schlesinger (2014), 21 had a statistically similar percentage of respondents selecting a given option. This is based on two-sample proportion tests where the $p$-value was less than 0.05 for only one task. The task for which the two data sets differ involved (second order) risk as it presented subjects with the choice of either $\$ 10$ with certainty or a $50-50$ gamble over $\$ 5$ or $\$ 15$, with the current subjects more likely to exhibit risk aversion. Still, given that this procedure involves 22 statistical tests, rejection of one at the $5 \%$ level is not surprising and any correction for multiple hypothesis testing would find this comparison to be insignificant.

Figure 2 compares the distribution of subject behavior between the two studies by risk apportionment level. Each panel reports the results of three statistical tests. The first asks whether or not the data from Deck and Schlesinger (2014), restricted to those tasks used in the current study, are generated by random behavior. The second statistical test asks whether or not the data from this replication are generated by random behavior. The third test asks whether the two data sets are generated from the same distribution. All three comparisons are based on the appropriate $\chi^{2}$ tests.

\footnotetext{
${ }^{12}$ No subject who participated in Deck and Schlesinger (2014) was allowed to participate in the current study. The directions were similar, but were altered to account for the reduction of compound lotteries and the inclusion of non-monetary risks.
} 


\section{Figure 2. Comparison of Replication and Restricted Original Data by Risk Apportionment Order}

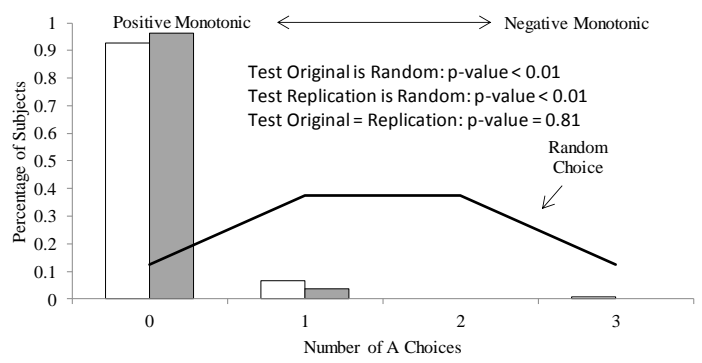

First-order

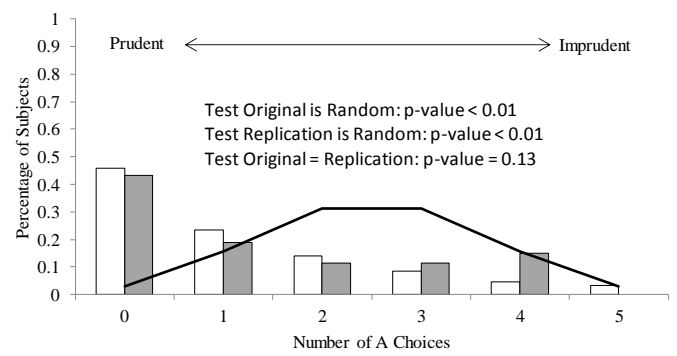

Third-order

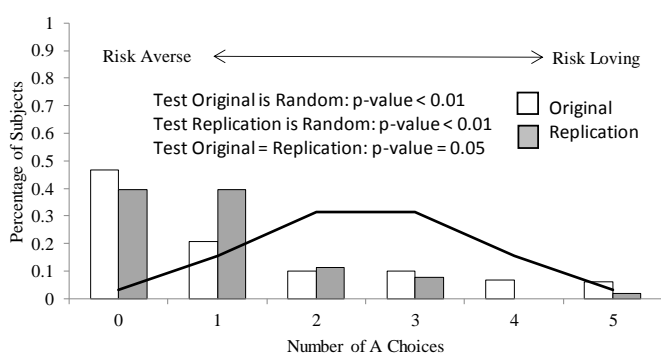

Second-order

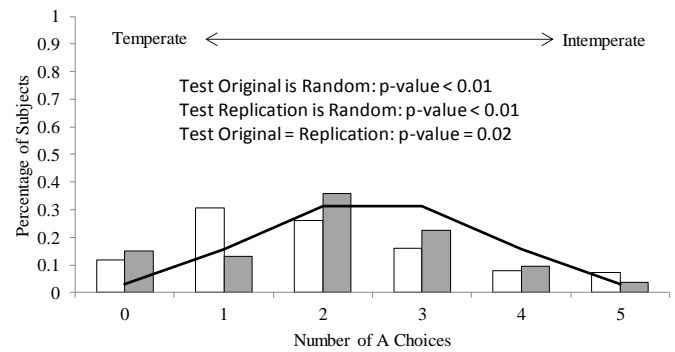

Fourth-order

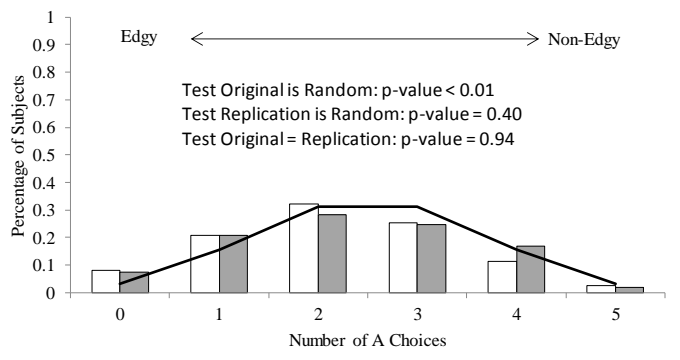

Fifth-order

The two datasets exhibit similar behavior for monotonicity, prudence, and edginess - the odd order risk apportionments. However, the two data sets are marginally different in terms of (second order) risk. The participants in the current study are somewhat more risk averse in aggregate than those in the original study. ${ }^{13}$ This is consistent with the individual task difference noted above. Temperance also differs between the two data sets, but this is not unexpected given that fewer subjects in this experiment are risk loving and that mixed risk averters and mixed risk loving subjects should behave differently when apportioning fourth order risks. For both data sets, behavior appears to approach randomness as the order being investigated increases, although only the replication data is not statistically different from random behavior in terms of edginess.

\footnotetext{
${ }^{13}$ Such a small percentage of the subjects are classified as risk loving that comparing the higher order risk attitudes of risk lovers and risk averters as in Deck and Schlesinger (2014) is not meaningful, but this is not the main focus of the current paper.
} 
As a final point of comparison between the two data sets we examine the relationship in risk taking behavior across orders by subjects. Table 3 shows the correlation in the percentage of risky choices by subjects for different pairs of risk apportionments for both data sets. One of the main findings in Deck and Schlesinger (2014) is that behavior for risk apportionment orders that differ by an even number are positively correlated while those differing by an odd number are not, consistent with people exhibiting a presence for either disaggregating bad outcomes or aggregating good outcomes. This pattern is generally found in our replication, with the exception that we observe a marginally significant negative correlation between temperance and edginess.

Table 3. Correlation in Behavior across Orders for Replication and Original Data Replication Data with Compound Lotteries

\begin{tabular}{|c|c|c|c|}
\hline & Risk & Prudence & Temperance \\
\hline Prudence & \multicolumn{3}{|l|}{0.145} \\
\hline Temperance & $0.420 * * *$ & \multicolumn{2}{|l|}{-0.057} \\
\hline Edginess & -0.012 & $0.232 *$ & \multirow[t]{2}{*}{$-0.253^{*}$} \\
\hline \multicolumn{3}{|c|}{ Restricted Original Data } & \\
\hline & Risk & Prudence & \multirow[t]{2}{*}{ Temperance } \\
\hline Prudence & 0.027 & & \\
\hline Temperance & $0.421 * * *$ & 0.053 & \\
\hline Edginess & $-0.156^{*}$ & $0.184^{* *}$ & -0.011 \\
\hline
\end{tabular}

Taken together, the evidence suggests that the compound lottery results of Deck and Schlesinger (2014) are robust. Given this, we now turn to our investigation of how the presentation format affects risk apportionment.

\subsection{Behavioral Effect from Reduction of Compound Lotteries}

We first examine behavior within reduced form lotteries and then compare behavior between compound and reduced form presentation of the lotteries. Table 4 is similar to Table 3, but with data from tasks with the reduced form lotteries for third and higher orders. The data in this table indicate that when compound lotteries are reduced, subjects again exhibit behavior consistent with the mixed risk averse and mixed risk loving pattern. However, further analysis suggests the similarity is an aggregate phenomenon as individual behavior varies based on whether or not lotteries are presented in reduced form or in compound form where one can easily assess the disaggregation of harms.

Table 4. Correlation in Behavior across Orders with Reduction of Compound Lotteries

$\begin{array}{llll} & \text { Risk } & \text { Prudence } & \text { Temperance } \\ \text { Prudence } & 0.086 & & \\ \text { Temperance } & 0.378 * * * & -0.080 & \\ \text { Edginess } & -0.067 & 0.267 * & 0.098\end{array}$

$*, * *, * * *$ denote significance at the $10 \%, 5 \%$, and $1 \%$ levels, respectively. 
Figure 3 is similar to Figure 2, but presents data from tasks with the reduction of compound lotteries. For comparison, data from the compound lottery tasks is again presented. The gray bars in Figure 3 are the same as the gray bars in Figure 2. No data are presented for first or second order risk apportionment as those tasks consist of either no lottery or only a single 50-50 gamble and thus do not involve compound lotteries. The panels in Figure 3 compare behavior with the reduction of compound lotteries to random behavior, but do not compare behavior between the reduced lotteries and the compound lotteries because the two sets of observations are coming from the same participants making the $\chi^{2}$ test inappropriate. Still, if the reduction of compound lotteries does not impact people's behavior, then one would expect to observe the same percentage of people in each classification for both presentations. This is not the case. In particular, Figure 3 suggests that in the aggregate people are more temperate and less edgy with compound lotteries. By comparison, Haering, et al. (2015) found that the reduction of compound lotteries led to less temperance and less prudence, but did not impact edginess. ${ }^{14}$ With the reduction of compound lotteries, a majority of the current subjects are classified as intemperate contrary to most previous experiments, but consistent with Deck and Schlesinger (2010) and Baillon, et al. (2016).

Figure 3. Behavior by Risk Apportionment Order with Reduction of Compound Lotteries

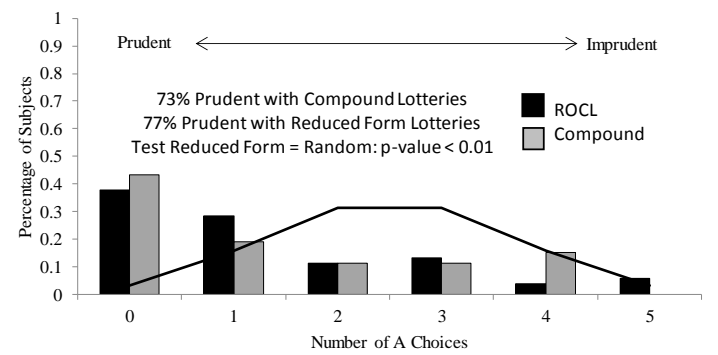

Third-order

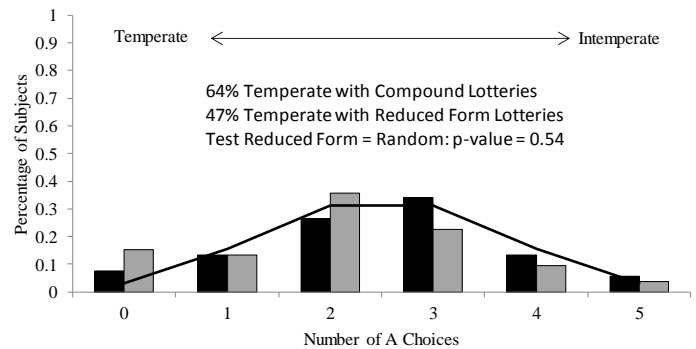

Fourth-order

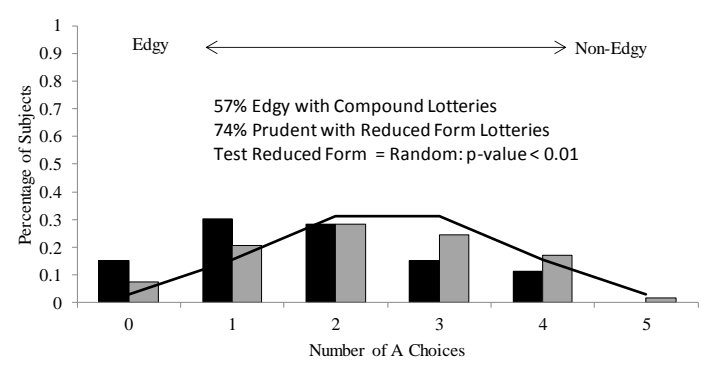

Fifth-order

We next take a closer look at how the reduction of compound lotteries impacts specific individuals by comparing their choices in one presentation format to their choices in the other format. Figure 4 plots individuals by the number of risky choices they make with compound lotteries and with reduced form lotteries for prudence, temperance, and edginess. Marker size indicates the percentage of subjects with

\footnotetext{
${ }^{14}$ Haering, et al. (2015) examine sixth order risk apportionment and do not observe behavioral differences between compound and reduced form lotteries.
} 
a given pair of classifications. Each panel also gives the percentage of subjects under each classification by their majority action. For example, $13 \%$ of participants are classified as prudent based upon their

Figure 4. Comparison of Risk Apportionment between Compound and Reduced Form Lotteries

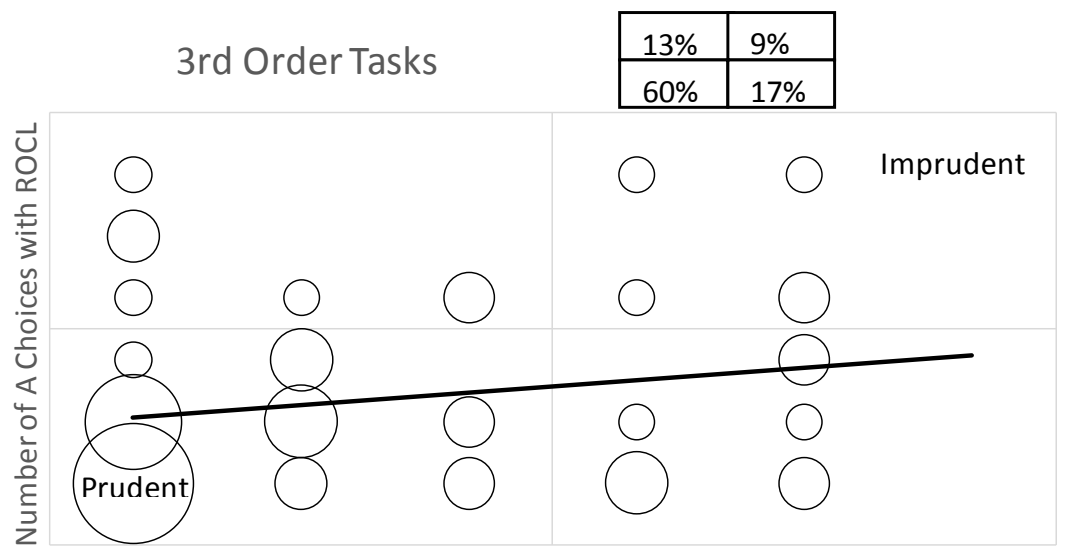

Number of A Choices with Compound Lotteries

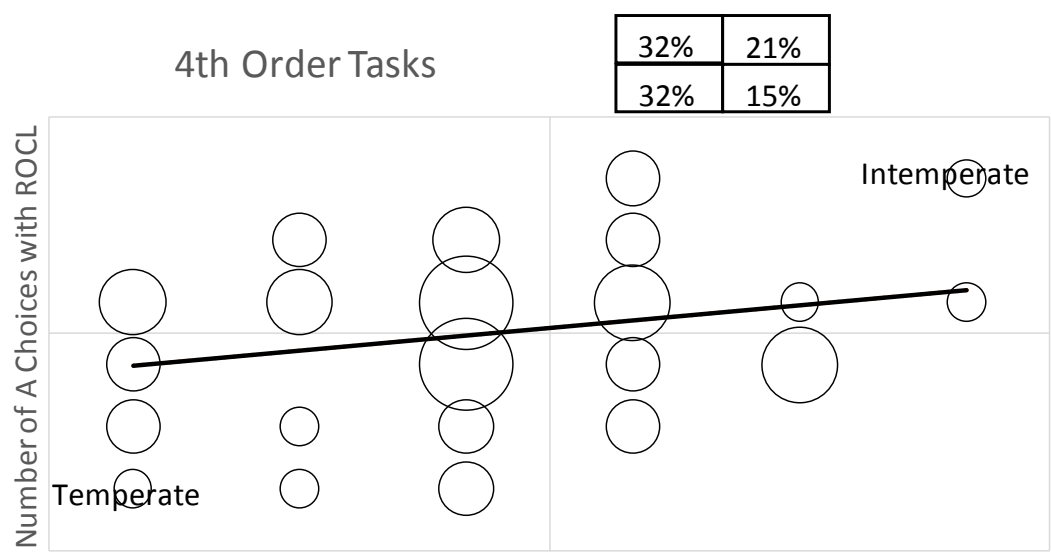

Number of A Choices with Compound Lotteries

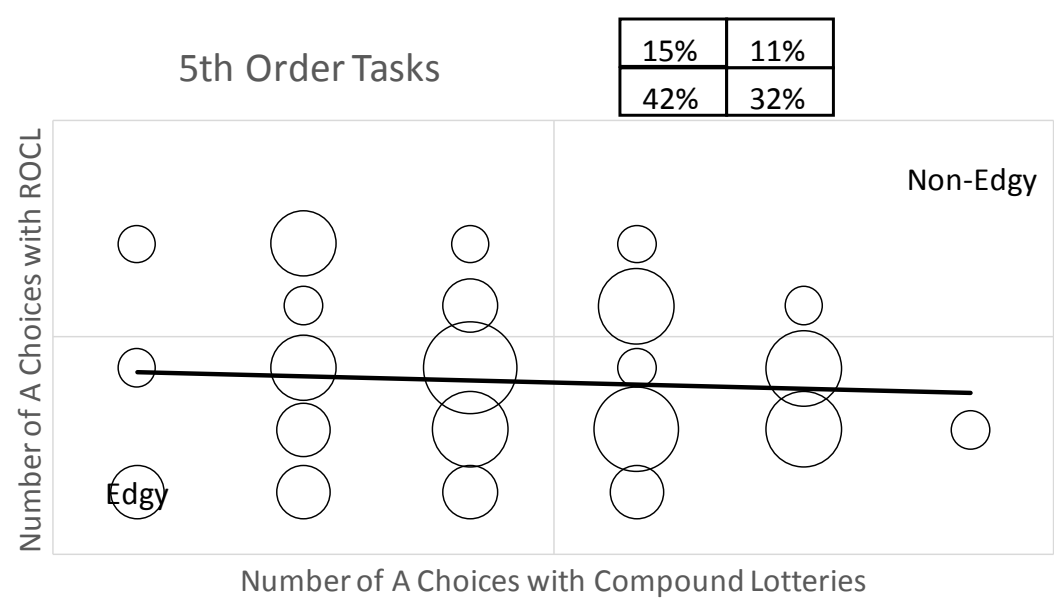


compound lottery choices and imprudent based on their reduced form lottery choices. If subjects are perfectly consistent between formats then everyone should appear somewhere along the diagonal from lower left to upper right. If people are largely consistent, but make occasional errors, then the data should still be clumped close to this diagonal line. The solid line represents the outcome from ordinary least squares regression. As is apparent in Figure 4, this is simply not the case. Instead, people's behavior under one format has little bearing on their choice under the other format. For prudence, the correlation between the number of risky choices a subject makes in the two formats is only 0.20 , which is not statistically significant ( $p$-value $=0.145$ ). For temperance, the correlation is 0.25 , which is marginally significant ( $p$-value $=0.070$ ). For edginess, the correlation is -0.071 , which is not statistically significant $(p$-value $=0.614) .^{15}$

As a final piece of evidence that people do not hold similar attitudes towards higher order risks across risk formats, we note that of the 15 tasks that were presented to subjects in both formats, in only one instance was the correlation in responses significant at the $95 \%$ confidence level. ${ }^{16}$ For the fourth order problem shown in rows 30 and 36 of Table 2 , the $p$-value $=0.001 .{ }^{17}$ The overall body of evidence indicates that people do not treat the same higher order risks similarly regardless of presentation format.

\subsection{Lotteries with monetary and non-monetary payoffs}

The first step in identifying the non-monetary risk preferences of the subjects involves determine the rank ordering of the tasty and weird flavor jelly beans. Tasks 39 and 40 in Table 1 are designed for this purpose. Overall, $51 \%$ of the subjects have the expected preference ranking tasty $\geq$ no jelly bean $\succeq$ weird. However, $23 \%$ like both flavors while $21 \%$ disliked both flavors. Three subjects reported weird $\geq$ no jelly bean $\geq$ tasty. Table 5 provides flavor level preferences.

\section{Table 5. Revealed Jelly Bean Preferences}

\begin{tabular}{lcc}
\multicolumn{1}{c}{ Flavor Pair } & Tasty $\geq$ No Jelly Bean & No Jelly Bean $\geq$ Weird \\
\hline Buttered Popcorn - Rotten Egg & 8 of 8 & 7 of 8 \\
Caramel Corn - Moldy Cheese & 9 of 11 & 7 of 11 \\
Coconut - Baby Wipe & 10 of 14 & 11 of 14 \\
Pear - Booger & 5 of 8 & 5 of 8 \\
Tutti Frutti - Stinky Socks & 7 of 12 & 8 of 12
\end{tabular}

\footnotetext{
${ }^{15}$ These three t-tests are based on the one-sided alternative that the correlation is positive since negative correlation is evidenced against the anticipated pattern.

${ }^{16}$ These tests were based on the one sided alternative as negative correlation is evidence against consistent behavior. Two other tasks were marginally significant each with $p$-values of 0.082 . Seven of the 15 tasks had negative correlations.

${ }^{17}$ Given the number of statistical tests that are being reported it is not surprising for at least one correlation to be reported as significantly positive, although this specific relationship would remain significant even after allowing for a Bonferroni correction.
} 
For subjects who prefer both flavors, a lottery over the two should be viewed as a relatively good outcome in comparison to not receiving any jelly bean. The opposite is true for subjects who dislike both flavors. For those who like one flavor and dislike the other flavor then the relative goodness of the jelly bean lottery depends on their risk tolerance and the payoff from the two flavors. Tasks 41,42 , and 43 are designed to measure this non-monetary risk attitude (conditional on also receiving \$5). Three subjects did not make consistent responses for Tasks 41-43 and are thus omitted from subsequent analysis. Table 6 shows how the (consistent) subjects valued the non-monetary lottery. The table reveals that subjects who liked both flavors do in fact place a positive value on the lottery, although the value is no more than $\$ 1$ for most of these subjects. Similarly, Table 6 reveals that subjects who dislike both flavors view the jelly bean lottery negatively with half of these subjects preferring to give up at least $\$ 1$ to avoid it. For the other two groups of subjects who like one flavor and dislike the other, most view the lottery as relatively bad. We acknowledge that those with preferences such that $\$ 1 \geq[\mathrm{W}, T]$ $\geq \$-1$ may not view $[\mathrm{W}, \mathrm{T}]$ as a zero mean risk as required by Eeckhoudt and Schlesinger (2006), although the responses of these subjects to tasks 39-43 are consistent with this interpretation.

Table 6. Assessments of Non-monetary Lottery

\begin{tabular}{lcccc} 
First Order Preference & {$[\mathrm{W}, \mathrm{T}] \geq \$ 1$} & $\$ 1 \geq[\mathrm{W}, \mathrm{T}] \geq \$ 0$ & $\$ 0 \geq[\mathrm{W}, \mathrm{T}] \geq \$-1$ & $\$-1 \geq[\mathrm{W}, \mathrm{T}]$ \\
\hline Tasty $\geq$ No Jelly Bean $\geq$ Weird & 2 & 7 & 18 & 0 \\
Weird, Tasty $\geq$ No Jelly Bean & 3 & 8 & 0 & 0 \\
No Jelly Bean $\geq$ Weird, Tasty & 0 & 0 & 5 & 5 \\
Weird $\geq$ No Jelly Bean $\geq$ Tasty & 0 & 0 & 2 & 0 \\
\hline
\end{tabular}

$[\mathrm{W}, \mathrm{T}]$ denotes the lottery that has a $50 \%$ chance of yielding a weird flavored jelly bean and a $50 \%$ chance of yielding a tasty flavored jelly bean.

We now examine to what degree subjects behave in a manner consistent with a general preference for combing good with good or good with bad in the tasks that involve non-monetary outcomes, although we recognize that this is not a strict test of Eeckhoudt, et al. (2009) given the possible non-zero mean nature of the jelly bean risks. Our design cannot identify which of the two jelly bean flavors subjects prefer, and thus consider relatively good, when both flavors are considered desirable or both are considered undesirable, so the remainder of this subsection excludes these subjects. ${ }^{18}$ Further, of the 29 remaining subjects, only 2 were ( $2^{\text {nd }}$ order) risk loving over money outcomes and only 2 preferred the weird flavor to the tasty flavor so these four subjects are also dropped. Table 7 gives the percentage of choices consistent with a preference for combining good with bad for the tasks involving jelly beans by the subjects who are risk averse over money and who have jelly bean preferences such that Tasty $\geq$ No

\footnotetext{
${ }^{18}$ From personal experience, we did not anticipate that many subjects would not view the tasty flavors as a good and the weird flavors as a bad.
} 
Jelly Bean $\geq$ Weird. ${ }^{19}$ It is obvious from this table that the subjects are not exhibiting a preference for combining good with bad.

\section{Table 7. Percentage of Subjects Disaggregating Harms in Choices with Jelly Beans Conditional on Being Risk Averse over Money and Tasty $\succeq$ No Jelly Bean $\succeq$ Weird}

\begin{tabular}{lcc} 
& $\begin{array}{c}\text { Subjects for whom } \\
{[\mathrm{W}, \mathrm{T}] \text { is Good }}\end{array}$ & $\begin{array}{c}\text { Subjects for whom } \\
{[\mathrm{W}, \mathrm{T}] \text { is Bad }}\end{array}$ \\
\cline { 2 - 3 } $3^{\text {rd }}$ Order & $67 \%$ & $39 \%$ \\
4 th Order & $63 \%$ & $49 \%$ \\
5 th Order & $50 \%$ & $49 \%$ \\
\hline [W, T] denotes the lottery that has a 50\% chance of yielding a weird \\
flavored jelly bean and a 50\% chance of yielding a tasty flavored jelly bean.
\end{tabular}

We also note that of the 17 subjects who are both risk averse for money payoffs and risk averse for the non-monetary lottery, the correlation in the percentage of A choices for $3^{\text {rd }}$ order tasks that do and do not involve the non-monetary lotteries is 0.528 , which is significant based on a one-tailed test with a $\mathrm{p}$ value $=0.028$. But, the correlations for $4^{\text {th }}$ and $5^{\text {th }}$ order tasks are virtually zero. The respective correlations are -0.003 and -0.031 and the one-sided p-values for testing that the correlations are positive are 0.504 and 0.546 . Looking at the 8 subjects who are risk averse over money and view the jelly bean lottery as a good, the correlation in behavior consistent with a preference for combing good with bad in tasks that do and do not involve non-monetary outcomes is -0.707 for $3^{\text {rd }}$ order tasks (one sided $p$-value $=0.980) .{ }^{20}$ For the $4^{\text {th }}$ and $5^{\text {th }}$ order tasks the correlations are 0.451 (one sided $p$-value $=$ 0.126 ) and -0.206 (one sided $p$-value $=0.690$ ), respectively. Again, this evidence suggests that the subjects do not follow a generalized mixed risk averse pattern when combining monetary and nonmonetary outcomes.

\section{Concluding Remarks}

This paper set out to explore the robustness of a behavioral pattern that has been reported in previous laboratory experiments. Specifically, a simple preference for combining a good outcome with a bad outcome yields mixed risk aversion when applied to higher order risk choices. Similarly, a preference for combining good outcomes (and hence also combining bad outcomes) yields mixed risk loving behavior. These types of preferences have an intuitive appeal and help explain why prudence is commonly found to be a more prevalent behavior than temperance since mixed risk averters and mixed risk loving people should agree on odd order risk apportionments but not on even ones.

\footnotetext{
${ }^{19}$ The fact that these subjects are risk averse for monetary outcomes implies that they do not have an underlying preference for combining good with good.

${ }^{20}$ This is actually strong evidence against a preference for combining good with bad although it is based on a very small sample size.
} 
At an aggregate level, our results with monetary payoffs are generally supportive of these two preference patterns. We successfully replicate previous experiments using the same tasks with compound lotteries. Previous use of compound lotteries was intended to facilitate identification of relatively good and bad payoff components, but many tasks that people face are not so neatly packaged. When we present subjects with the same set of lotteries presented in reduced form, the same general pattern emerges. However, once one looks at the individual level it is clear that subjects are treating the lotteries differently.

Our robustness check also involved non-monetary outcomes. Here the pattern did not conform well to the combining good with good or good with bad prediction as subjects did not combine monetary and non-monetary outcomes in the same manner in which they combined different monetary outcomes. Taken as a whole, our experiments indicate that the notion of people having basic preferences for aggregating or disaggregating harms is a reasonable approach to modeling behavior in some situations, but may not be appropriate in others. Of course, further research is warranted before strong conclusions can be reached or clear domains of applicability can be drawn.

\section{References}

Baillon, A., H. Schlesinger, and G. van de Kuilen. 2016, "Measuring Higher Order Ambiguity Preferences." Working Paper, Tilburg University.

Caballé, J. and A. Pomansky, 1995. “Mixed Risk Aversion." Journal of Economic Theory 71, 485-513.

Crainich, D., L. Eeckhoudt, and A. Trannoy, 2013. "Even (Mixed) Risk Lovers are Prudent." American Economic Review 103, 1529-1535.

Deck, C. and H. Schlesinger, 2010. "Exploring Higher-Order Risk Effects" Review of Economic Studies 77, 1403-1420.

Deck, C. and H. Schlesinger, 2014. "Consistency of Higher Order Risk Preferences," Econometrica 82, 1913-1943.

Dréze, J. and F. Modigliani, 1972. "Consumption Decisions under Uncertainty." Journal of Economic Theory 5, 308-335.

Ebert, S. and G. van de Kuilen, 2015. "Measuring Multivariate Risk Preferences." Working Paper, Tilburg University.

Ebert, S. and D. Wiesen, 2011. “An Experimental Methodology Testing for Prudence and Third-Order Preferences." Management Science 57, 1334-1349.

Ebert, S. and D. Wiesen, 2014. "Joint Measurement of Risk Aversion, Prudence, and Temperance." Journal of Risk and Uncertainty 48, 231-252.

Ebert, S., D. Nocetti, and H. Schlesinger, 2016. "Greater Mutual Aggravation." Working Paper, Tilburg University. 
Eeckhoudt, L. and H. Schlesinger, 2006. "Putting Risk in its Proper Place." American Economic Review 96, 280-89

Eeckhoudt, L. B. Rey and H. Schlesinger, 200. "A Good Sing for Multivariate Risk Taking." Management Science 57, 1334-1349.

Eeckhoudt, L., H. Schlesinger and I. Tsetlin, 2009. "Apportioning of Risks via Stochastic Dominance." Journal of Economic Theory 144, 994-1003.

Harrison, G. J. Martinez-Correa, and J. T. Swarthout, 2015. "Reduction of Compound Lotteries with Objective Probabilities: Theory and Evidence." Journal of Economic Behavior and Organization 119, 32-55.

Haering, A., T. Heinrich, and T. Mayrhofer, 2015. "Exploring the Consistency of Higher-Order Risk Preferences." Mimeo.

Kimball, M.S., 1990. "Precautionary Savings in the Small and in the Large." Econometrica 58, 53-73.

Leland, H.E., 1968. "Saving and Uncertainty: The Precautionary Demand for Saving." Quarterly Journal of Economics 82, 465-73.

Maier, J. and M. Rüger, 2012 "Experimental Evidence on Higher-Order Risk Preferences with Real Monetary Losses." University of Munich Working Paper.

Noussair, C.N., S.T. Trautmann, G. vd Kuilen, 2014. "Higher Order Risk Attitudes, Demographics, and Saving." Review of Economic Studies, forthcoming.

Sandmo, A., 1970. "The Effect of Uncertainty on Saving Decisions." Review of Economic Studies 37, 35360 .

Smith, V., 1982. "Microeconomic Systems as an Experimental Science." American Economic Review 72, 923-955. 


\section{Appendix. Subject Instructions}

\section{Page 1.}

You are participating in a research study on decision making under uncertainty. At the end of the study you will be paid your earnings in cash and it is important that you understand how your decisions affect your payoff. If you have questions at any point, please let a researcher know and someone will assist you. Otherwise, please do not talk during this study and please turn off all cell phones.

In this study there is a series of 52 tasks. Each task involves choosing between Option A and Option B. Once you have completed these tasks, one of the 52 tasks will be randomly selected to determine your payoff.

\section{Page 2.}

Each option will involve guaranteed payoffs or lotteries with amounts of money, flavored jelly beans, or both. The JellyBelly company produces jelly beans in a variety of flavors that are available for purchase at various specialty stores. Their Bean Boozled product line consists of pairs of "Tasty" and "Weird" flavors that are visually indistinguishable. You have already been given a slip of paper that identifies the "Tasty" and "Weird" flavor randomly selected to apply to your jelly bean choices.

\section{Page 3.}

A lottery is represented as a circle with one or more lines through the middle and looks like a pizza that has been sliced. Each slice will contain some combination of money, flavored jelly beans, and additional lotteries. The size of each slice indicates the relative chance that you would receive those items. For

\section{$\$ 8 \$ 12)$}

example, 1 is a lottery in which you would receive either $\$ 8$ or $\$ 12$, each with a $50 \%$ chance since the line splits the circle in half. There are no optical illusions. Slices will either be $1 / 2=50 \%, 1 / 4=25 \%$, $1 / 8=12.5 \%$, or $1 / 16=6.25 \%$ of the whole circle. To determine the outcome of any lottery, we will use a spinner. You are welcome to inspect the spinner at any point. 
Page 4.

In some cases, one of the items in a lottery may be another lottery. For example,

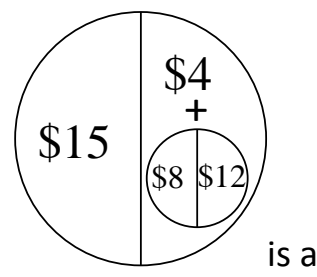
lottery where you have a $1 / 2$ chance of receiving $\$ 15$ and a $1 / 2$ chance of receiving $\$ 4$ plus the lottery $\$ 8 \$ 12)$

Page 5.

For some tasks, there will be multiple levels of lotteries in lotteries. In
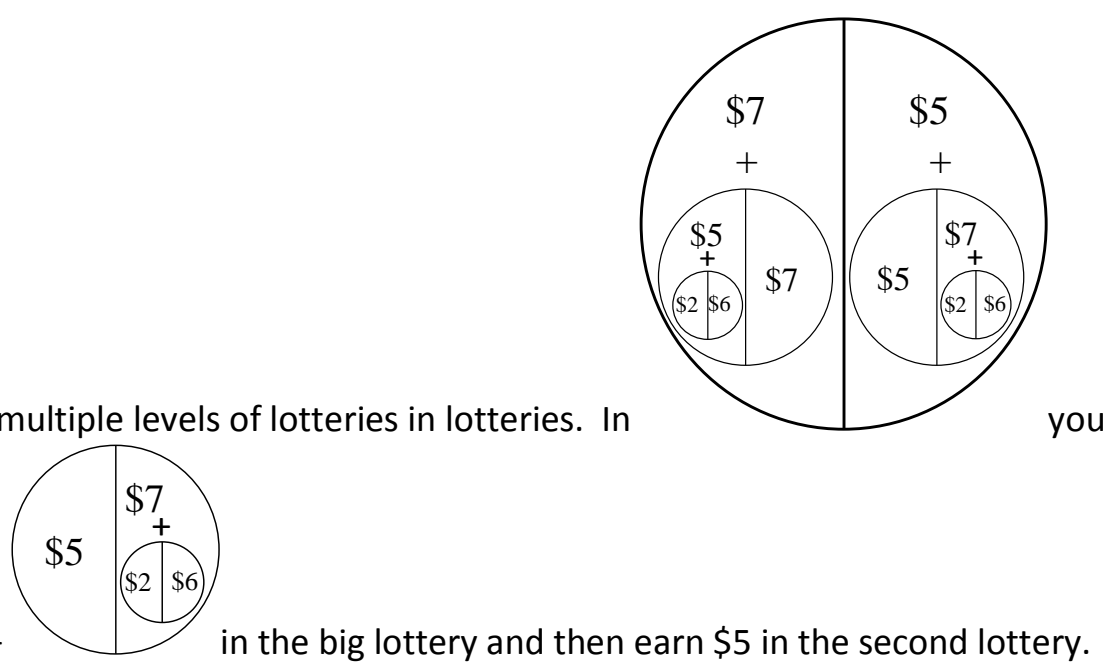

in the big lottery and then earn $\$ 5$ in the second lottery.

could earn $\$ 10$ if you get $\$ 5+$

nce. Alternatively, you could earn $\$ 14$ with a $50 \%$ chance. Notice that you could earn $\$ 14$ by 1 ) earning $\$ 7$ (in the big lottery) + \$5 (in the middle lottery) $+\$ 2$ (in the little lottery) which happens with a $1 / 2 \times 1 / 2 \times 1 / 2=1 / 8=12.5 \%$ chance or 2 ) earning $\$ 7$ (in the big lottery) $+\$ 7$ (in the middle lottery) which happens with a $1 / 2 \times 1 / 2=1 / 4=25 \%$ chance, or 3 ) earning $\$ 5$ (in the big lottery) $+\$ 7$ (in the middle lottery) $+\$ 2$ (in the little lottery) which happens with a $1 / 2 \times 1 / 2 \times$ $1 / 2=1 / 8=12.5 \%$ chance. Finally there are two ways that you could earn $\$ 18$ which occurs with a $1 / 2 \times$ $1 / 2 \times 1 / 2+1 / 2 \times 1 / 2 \times 1 / 2=25 \%$ chance. 
Page 6.

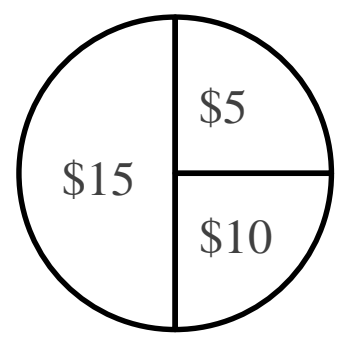

Let's look at another example.

is a lottery where there is a $1 / 4$

chance you receive $\$ 5$, a $1 / 4$ chance you receive $\$ 10$, and a $1 / 2$ chance you receive $\$ 15$.

\section{Page 7.}

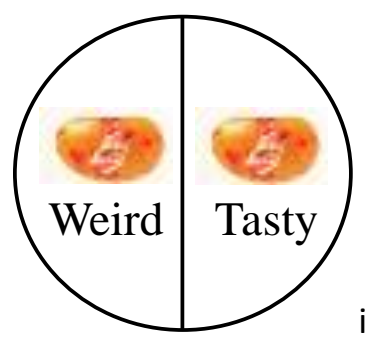

is a lottery where there is a $1 / 2$ chance that you receive your "Tasty" flavored jelly bean and a $1 / 2$ chance you receive your "Weird" flavor. If the randomly selected task for which you are to be paid involves a jelly bean, then you must chew and consume (keeping the chewed jelly bean in your mouth for 10 seconds) the appropriate jelly bean to receive any cash payment. 